\title{
Analysis on University Education Reform and Teaching based on Computer Multimedia and Network Teaching Platform
}

\author{
MaoHong Sun ${ }^{1}$, Rongchao Hao ${ }^{1}$, BaoDi Wang ${ }^{2}$, Guohua Wang ${ }^{1}$, Jian ge ${ }^{1}$, \\ Siqi Yue ${ }^{3}$ and Chunwang Yue, \\ ${ }^{1}$ College of Animal Science and Technology, Hebei North University, HeBei \\ Zhangjiakou 075100, P. R. China \\ ${ }^{2}$ College of Agriculture Science and Technology, Hebei North University, HeBei \\ Zhangjiakou 075100, P. R. China \\ ${ }^{3}$ Henan University of Science and Technology, Henan,471023, China \\ *Corresponding author: Chun-wang Yue, sunmaohong0313@163.com
}

\begin{abstract}
Computer multimedia provides a modern teaching means for classroom teaching, which shows great advantage in the reasonable control of teaching resources. In this paper, the authors analyze university education reform and teaching based on computer multimedia and network teaching platform. It can be seen that the most universities have implemented the multimedia teaching; the teaching mode has changed from the traditional teaching mode to the modern teaching mode. In terms of curriculum planning, teachers can use the network teaching platform and teaching courseware to complete the teaching. In terms of learning support, the platform could provide a variety of common support tools, such as online classroom, answering system. Overall, multimedia teaching can effectively provide teaching efficiency.
\end{abstract}

Keywords: Computer multimedia, Network teaching platform, Education reform, Wisdom sharing

\section{Introduction}

Twenty-first Century is the information age, the level of information has become a measure of a country's modernization level and comprehensive national strength of the important indicators[1]. At present, both developing and developed countries, in order to cope with the challenges of the new situation, seek to find a way of education reform, speeding up its modernization level and their comprehensive national strength. However, the development path of cultivating talents dialysis modernization level and the comprehensive national strength, depends on the talent so its root the stream of self education, which countries are speeding up the implementation of the deployment strategy, technological innovation strategy, seize the commanding heights of forming talents in the field of education, that is to advocate the education reform, to promote the information of higher education development[2-3]. With the continuous development of education information, information technology education in the course of higher education has been widely used in the process of extensive promotion and practical application. As the multimedia technology is a part of information technology, it is also an important part of educational information, making the multimedia teaching has become an important part of the teaching reform.

Multimedia teaching depends on multimedia technology, it is the computer technology and communication technology integration, integrated processing, storage and transmission of multimedia information related to digital technology[4]. Therefore, with the rapid development of information technology in education, multimedia synchronous rapid development and practical application on the basis of the original, found a role in 
education and teaching in higher education, the teaching environment, teaching multimedia teaching in the forefront[5]. The national institutions of higher learning in education and teaching to intensify the implementation of multimedia teaching, accelerate the expansion of infrastructure construction of multimedia classroom, and multimedia teaching contest held at all levels; with the development of international modern multimedia technology and modern education idea of the rapid update and convergence, at this stage of the classroom teaching mode from the traditional way of teaching reform for modern teaching and traditional teaching the mode of combining[6]. Because of the multimedia teaching in the teaching process of high education in outstanding advantages and great potential, the multimedia teaching has become a key link in enhancing the quality of education and teaching, multimedia teaching, multimedia teaching is to explore research and develop innovative space.

\section{Multimedia Technology and Network Platform}

\subsection{Computer Assisted Multimedia}

From the historical development of multimedia teaching, multimedia teaching originated from computer assisted instruction. It has inherited the birth of the Second World War in the slide, projection, recording, broadcasting, television and other media education theory, but also the product of the information age, along with the development of multimedia technology, in the past development, not only has a profound impact on the traditional teaching and learning of modern multimedia computer technology network technology, wired and wireless technology, and to learn communication, distance education, information technology and curriculum integration, the theory of behaviorism, cognitive theory, psychology theory, always stand in the development of cutting-edge modern multimedia teaching, which has an important effect in the field of education, the education reform era[7-8]. The multimedia computer is called a revolution of computer information technology, it has the ability to comprehensive processing character, image, audio, video, and shows the multimedia computer in the education of special talent, soon become an important direction of the development of computer assisted instruction, and to track the multimedia teaching in the teaching process[9]. There is no doubt that the multimedia teaching theory and practice construction forming at the same time, along with the coverage of the multimedia classroom system in university network format, making multimedia teaching further foothold, find the ultimate goal of education; in addition, provides strong technical support conditions for the development of contemporary modern computer technology, network technology, communication technology and multimedia technology, database technology and artificial intelligence technology for the development of multimedia teaching, is trying to become the modern multimedia teaching; multimedia learning in the field of famous scholar Mayer pointed out: how to use multimedia to promote people's learning is the core problem in the research of multimedia teaching. 


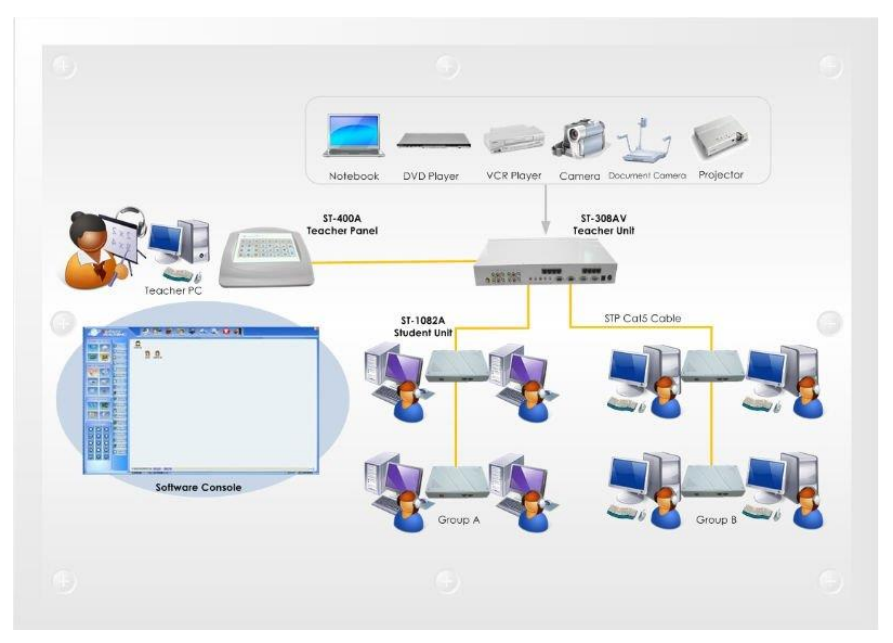

Figure 1. Multimedia classroom

Multimedia technology is an important part of modern education, the development of multimedia technology is a product of the development of science and technology and the progress of the times, teaching the use of multimedia technology to service under the new situation, to enrich the content of classroom teaching, arouse students' attention, optimize the teaching process, improve teaching effect, and stimulate students' innovative consciousness and culture the students to analyze and solve the problems of practical ability[10]. According to the definition of multimedia technology, some scholars have defined as: multimedia technology is the use of computer technology, network technology, on the map, text, sound, image and other information for digital processing technology.

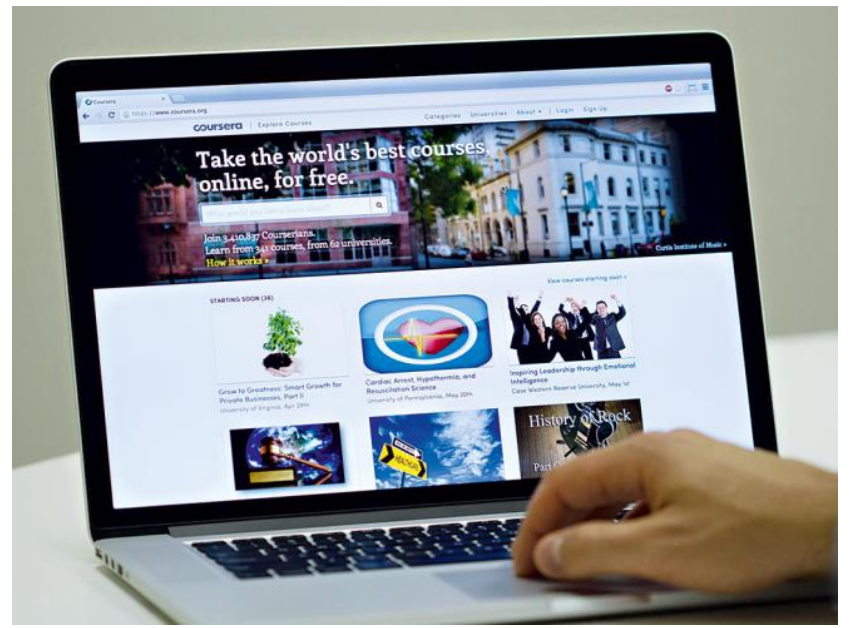

Figure 2. Network Course Search

\subsection{Network teaching platform}

The popularity of E-Learning promoted the development of EB W learning management system. The progress of computer technology and the concept of learning evolution is the power source to promote the continuous development of the LM S. The network teaching platform plays a fundamental role in supporting E-Learning in recent years has been widely used. Since the emergence of the first network teaching platform $4 \mathrm{~A}$ in China, there have been more than a dozen similar software products; foreign network teaching support system is also a massive entry into the Chinese market, such as Blackboard. However, no real law of the development of teaching and research network 
function design of most platforms, are blind mutual reference and imitate the existing network teaching platform, network teaching platform function and form more homogeneous, the function of hovering at a low level, not keep up with the development of the new teaching and technology trends.

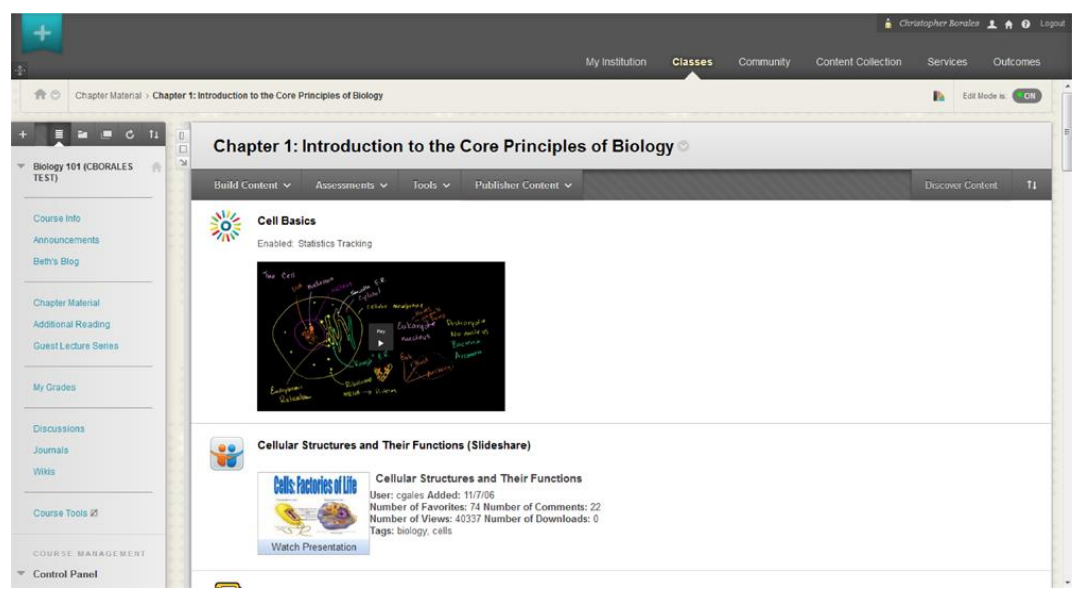

Figure 3. Blackboard Network Teaching Platform

As a relatively complete support environment of network teaching and learning, the network teaching platform should be able to support teachers' teaching and students' learning in a comprehensive and effective way. Different learning ideas form different teaching paradigms, which lead to different teaching modes, teaching practice and learning development mode, and put forward different requirements to the network teaching platform. At present, the paradigm of network teaching can be divided into two major categories: knowledge transfer and knowledge construction. Knowledge transfer teaching paradigm is based on the theory of behavior and cognition. It is considered that learning is the link between stimulus and response, emphasizes knowledge transfer and access, and emphasizes the role of reinforcement. The typical characteristic of network teaching this teaching under the paradigm is: teachers in guiding the clear teaching objectives, teaching through careful design, through a variety of real-time courseware, and other ways to explain the present teaching materials and teaching content to students, emphasizing and strengthening of knowledge acquisition.. Therefore, under the guidance of this teaching mode, the network teaching platform has the following characteristics:

1) Emphasis on the management of curriculum content, curriculum resources, as well as the delivery of content, such as real-time video, courseware

2) Curriculum planning, network teaching platform need to provide courseware making tools to facilitate teachers to prepare a variety of materials

3) Learning support, the platform needs to provide a variety of common support tools, support for teachers to students of synchronous and asynchronous counseling, such as BBS, question answering system, etc.;

4) Online teaching evaluation, emphasis on online testing, mainly based on the evaluation of the results of the examination evaluation, through the examination results to understand the students' mastery of learning materials.

Web 2.0 technology development calls for the emergence of a new network teaching service system architecture, but also to promote the new development of the network teaching platform. The network teaching platform of the next stage of development will fully reflect the core idea of Web 2.0, network teaching platform under the guidance of the concept of emphasizing the construction of virtual community, knowledge sharing and 
rich user experience; that through the network to use the collective wisdom, let all people have the opportunity to express their voice; promote the individual development by sharing each other's opinions, ideas, resources, emphasize the learning process, emphasizing the platform and contents of the construction to the center, emphasizing the distributed cognition, with the cognitive construction network teaching paradigm is consistent.

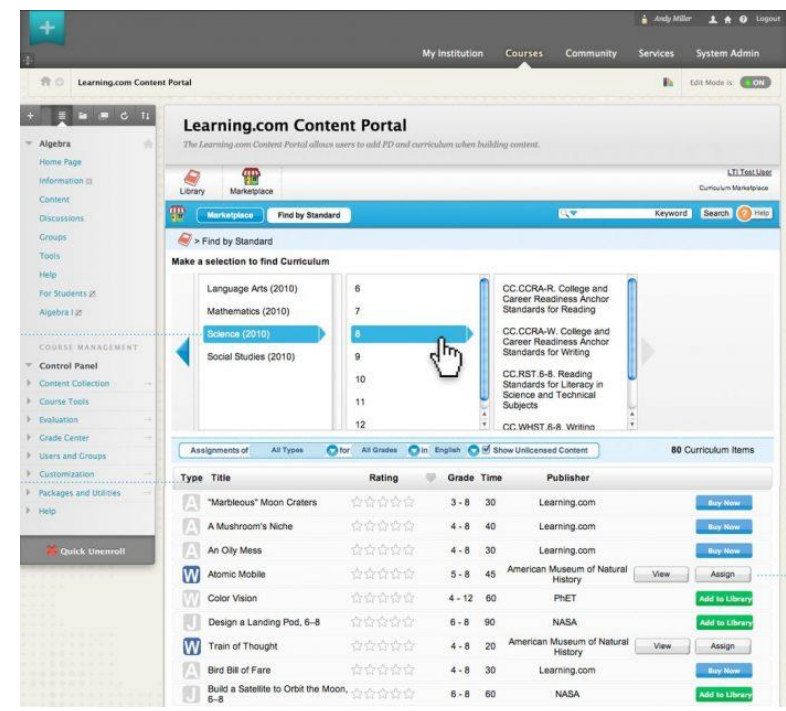

Figure 4. Online Course Selection System

\section{The Application of Multimedia Teaching in College Education}

\subsection{The Development Trend of Multimedia Teaching Platform}

Through the analysis of two factors, the influence of network teaching platform development and change we think, with a better understanding of the digital learning and gradually recognized and rapid development as well as the relevant standards and technology, network teaching platform of the next stage of development will have a clear trend and characteristics of the following aspects:

- Standardization: The formulation of E-Learning standard and the popularity of more and more attention, its design and development must be considered compatible with mainstream international standard, otherwise the data cannot be other platform recognition and processing, are not compatible with mainstream manufacturers, curriculum content and resources, application will have great resistance. Therefore, standardization is the inevitable trend of the future development of the network teaching platform.

- Strong openness: The popularity of E-Learning and deep application platform requires strong open, one hand can exchange data and other related systems, interoperability, on the other hand, can better adapt to the rapidly changing demand, through a small price service upgrade or replacement process reengineering can achieve on-demand requirements. A strong open network teaching platform can be in the future to require complex systems in collaboration and dynamic evolution of the environment to maintain a strong competitive 


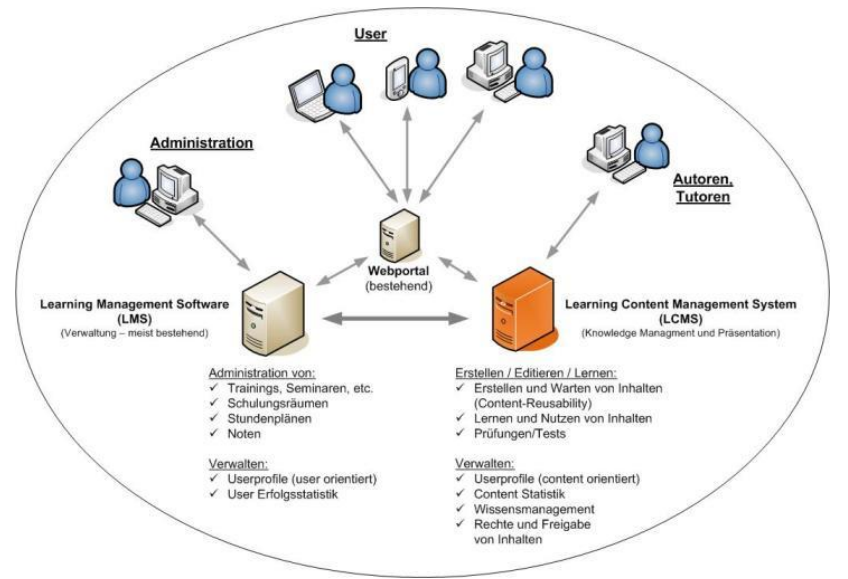

Figure 5. E-Learning Environment

- Individualization: Compared with face-to-face environment, individual differences under the environment of E-Learning learners is more significant, therefore, the network teaching platform of the excellent learners must meet the personalized needs of different styles, different starting point for learners to provide appropriate learning content, learning activities and other learning support services, and the development of related standards and technologies for this requirement provided objective conditions.

- Intelligence: The development of ontology technology and artificial intelligence technology has laid the foundation for the development of network teaching platform. Intelligent network teaching platform will be able to students' learning and teachers' teaching to provide more powerful support, reduce simple and repetitive operation, but also to provide teachers and students after analysis and treatment proposals on teaching and learning.

- Advanced intelligence sharing: The traditional network teaching platform emphasizes sharing learning objects, network teaching platform for the next generation will be based on the wisdom of senior emphasizes design level of sharing and reusing, not only to the quality teaching content with the use of information technology to share, let more excellent teaching design for more teachers and learners enjoy.

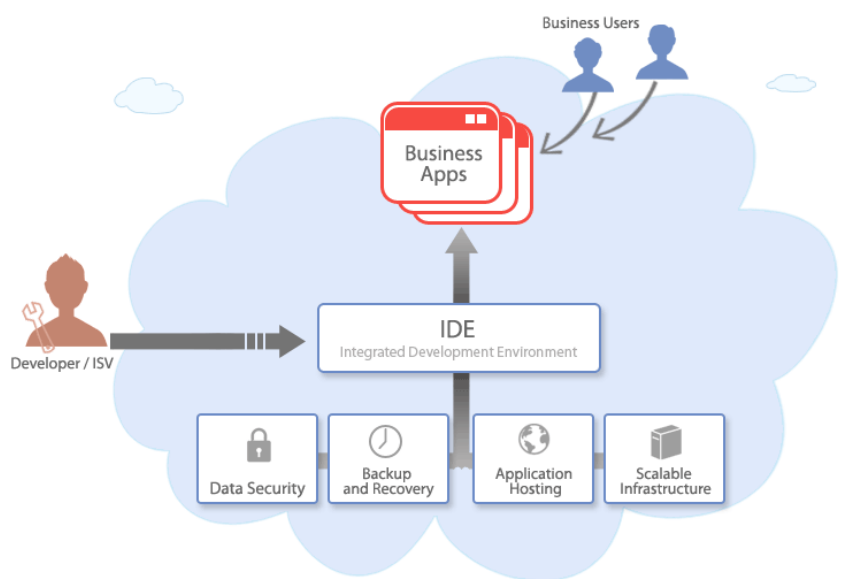

Figure 6. Intelligent Teaching APP 
The early development of network teaching platform is the use of modular software development model. The platform products can be seen as a series of components with specific functions, as a complete system can be decomposed into a series of functional modules, the interactions between these modules form all the function of the system. In this development mode, a complete network teaching platform is broken down into a series of functional modules, each module complete the corresponding sub functions, such as answering, curriculum, discussion and communication, etc.. Development of the time, different developers are responsible for the development of different modules. After the development of each module is completed, and then they are integrated, the interaction between these modules to form a network of all the functions of the teaching platform. In the modular development mode of the network teaching platform, each module is designed by different designers to achieve the division of labor. Modular software development can reduce a lot of repetitive work in software development activities, can improve software productivity, reduce development costs and shorten the development cycle.

\subsection{Problems in Multimedia Teaching}

Multimedia provides a modern teaching means for classroom teaching, which shows a great advantage in the reasonable control of traditional classroom teaching resources. It's highly integrated information makes a variety of film and television, animation, simulation, sound and text can be leisure less transition and switching, and formed some unique methods of multimedia teaching, showing creativity, flexibility and comprehensive advantages of height, in the classroom teaching has shown its great education the advantage, but in actual classroom teaching the use of multimedia there are unsatisfactory.

- Use purpose is not clear: The university classroom teaching, the application of multimedia means its fundamental purpose is to optimize the structure of classroom teaching, to provide various stimulation signals to effectively attract the attention of students, stimulate students' interest in learning, to solve practical problems in teaching, to improve the effect of classroom teaching. But in many cases, teachers' practical needs but not teaching, not teaching design necessary and blind use of multimedia, the result has not obtained the expected effect, but the effect to achieve the goal of teaching.

- Over exaggeration of the role of multimedia teaching: We make full use of multimedia technology to master the knowledge, understand the world, enjoy the joy of learning at the same time, some teachers and lead to "media first" wrong idea due to exaggerate the role of multimedia teaching in the classroom teaching, that only the use of the multimedia in order to obtain the best teaching effect, is the high level of teaching with "technical content" and in order to achieve the teaching of "keeping pace with the times".

- Confusion of the main and auxiliary relations: Multimedia teaching is a computer powerful information processing capabilities to solve some difficult problems in teaching, strengthen the need to fully grasp some key issues, some key issues highlighted in the teaching, play the role of teachers in the classroom teaching, teachers completed part of the work. Under normal circumstances, multimedia assisted teaching, teachers play a leading role, and in some of the discussion or students to use multimedia autonomous learning process, the media also only play a supporting role. Many teachers are not aware of this relationship, can not correctly handle the relationship between teachers and multimedia, to play its due role in education. 


\section{Analysis on the Countermeasures of Multimedia Teaching Reform}

\subsection{Establish the Correct Concept of Multimedia}

(1) media choice optimization. In the classroom teaching, not all teaching need to use the multimedia, the teacher should according to the teaching content of the actual needs, determine whether the use of multimedia, the use of multimedia, to avoid the blind use of multimedia. In addition, the use of the principle of optimization to choose, to achieve teaching objectives with the traditional media, we do not have modern media; to be able to use low-cost media to achieve, we do not have the high cost of media.

(2) the combination of multimedia teaching and traditional media teaching. The advantage of multimedia teaching has been recognized by everyone, but it also has defects or deficiencies. For teaching, there is no universal teaching media. Therefore, the process of teachers' teaching in the use of multimedia, to fully absorb the advantages of traditional media teaching, combine traditional media teaching and multimedia teaching, to achieve mutual complementarily and mutual complement, not superstition or excessive dependence on multimedia means, to correctly handle the relationship, traditional teaching methods and modern teaching media the media means each in his element, complement each other.

(3) multimedia is a means of teaching and learning. Multimedia with its powerful function, in the classroom teaching can help teachers to complete the teaching goal, but also can help students more easily and freely to understand and master the knowledge learned. As a kind of auxiliary "teaching" means of multimedia in the classroom teaching, but also can be used as a means to help students to "learn", but the role of teachers is multimedia cannot be replaced, only under the guidance of teachers in multimedia can play the best and largest teaching function, to achieve the optimization goal of education.

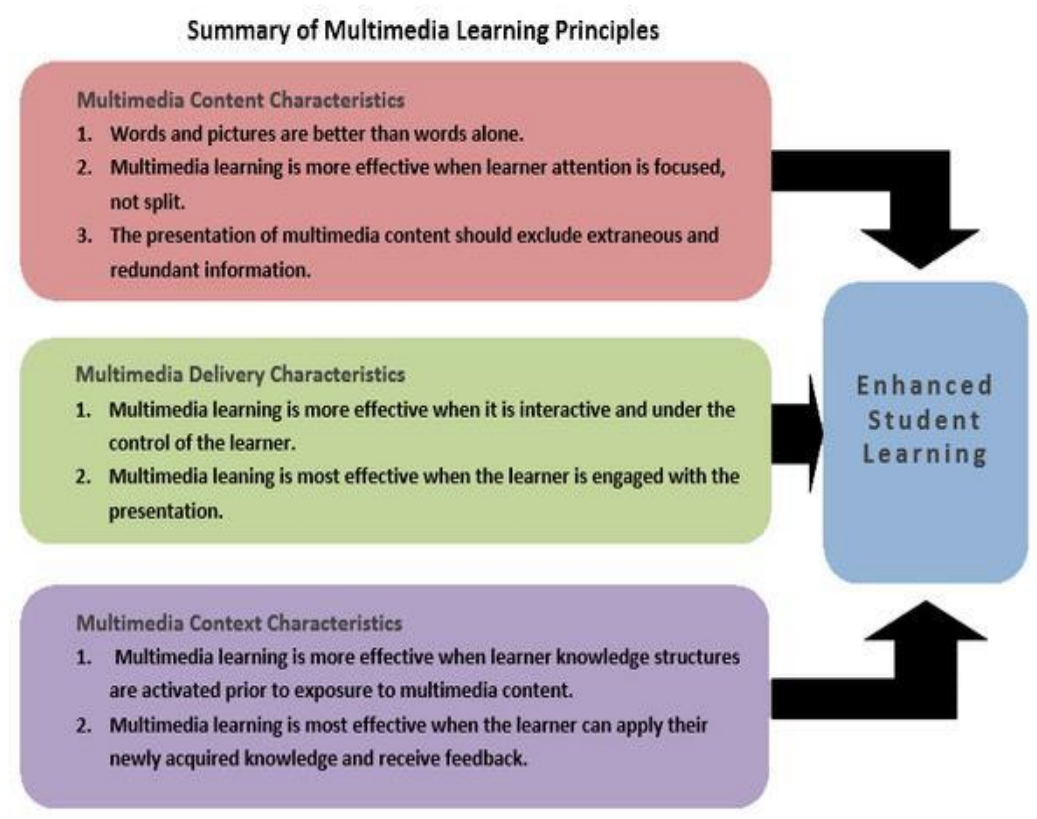

Figure 7. The Principle of Multimedia Learning 


\subsection{Exploring Effective Multimedia Classroom Teaching Methods}

(1) pay attention to the design of multimedia teaching.

Teaching design is the soul of optimizing the teaching process. In order to improve the effect of applying multimedia in classroom teaching, we must pay attention to the teaching design, make the teaching process always through the guiding ideology of teaching design, and form the correct multimedia teaching idea. In the teaching design, the multimedia application is to realize the teaching goal service, it has provided the perceptual material, has reconstructed the solution teaching key and the difficult question situation, promoted the student thought development. Therefore, in the teaching design, teachers must fully consider the reasonable selection and application of multimedia, comprehensive, systematic processing of the relationship between multimedia and other teaching elements.

(2) effective design of teaching process

The application of multimedia in teaching is to achieve a better teaching effect, which must be a reasonable planning of teaching process, also known as the design of teaching operation. In the whole process of teaching teachers should not just sit in front of the screen to manipulate the mouse, the screen changes, to walk properly, sufficient to prompt, express and exchange of information to prevent the use of body language, teaching ideas around by the media, teaching style is overwhelmed by the media.

(3) accurately grasp the opportunity, pay attention to the rhythm of the classroom.

As a result of the introduction of multimedia means, greatly enriched the amount of information in classroom teaching, which provides a convenient condition for students to learn. But if the amount of information presented too much, too (because of the teaching content teaching program does not require teachers on the blackboard, makes some teachers can't grasp the rhythm of teaching), beyond the students' thinking rhythm, makes it difficult for students to accept and understand. So in the teaching should be properly controlled presentation, presentation and teaching time and rhythm, set aside some time for the students to think. When necessary, the temporary closure of the screen display, forcing students to leave the screen to get more time to think.

(4) strengthen the direct communication between teachers and students.

Multimedia teaching has the advantages of the maximum interaction between teachers, media and students, which can make all kinds of multimedia teaching resources be fully utilized. However, the direct interpersonal interaction between teachers and students has been weakened. Teaching mainly through the human machine interaction, which will bring some negative effects on students' thoughts and psychology. Because of the physical characteristics of multimedia itself determines the mode of presentation is stylized (although we use a variety of display effects), if the students face this kind of situation, it will cause annoying screen psychology, the emotion between teachers and students will gradually dim and distant, will eventually lead to the loss of emotion. Therefore, teachers should seize the opportune moment to set the time to communicate with the students, to eliminate or avoid the negative effect.

\section{Conclusion}

Network teaching platform is the most important supporting environment for network teaching and learning, and its design concept and function quality will directly affect the quality of network teaching and learning. The progress of computer technology and the 
concept of learning reform is the core factor to promote the continuous development of the network teaching platform, design and development of network teaching platform should always pay attention to the two aspects of the trend and progress of technology progress and learning concept and the results of changes when applied to many aspects of platform, and constantly promote the teaching platform design the concept, system structure, function and evolution. Blind cross reference and imitation will make the domestic network teaching platform hovering at a low level, only grasping the changes of E-Learning demand, the development and application of domestic network teaching platform to keep pace with the times, not only the development trend will always lag behind E-Learning.

\section{Acknowledgments}

This study was financed by the Hebei North University teaching reform project: The teaching reform of the (animal husbandry); Animal nutrition and feed science in Hebei Province, the focus of the development of science.

\section{References}

[1] R. A. Sabella, "School counselors perceived importance of counseling technology competencies", Computers in Human Behavior, vol. 26, (2010), pp. 609-617.

[2] N. R. Mastroleo and R. Turrisi, "Examination of posttraining supervision of peer counselors in a motivational enhancement intervention to reduce drinking in a sample of heavy-drinking college students", Journal of Substance Abuse Treatment, vol. 39, (2010), pp. 289-297.

[3] Z. Huang and M. Benyoucef, "From e-commerce to social commerce: A close look at design features", Electronic Commerce Research and Applications, vol. 12, no. 4, (2013), pp. 246-259.

[4] C. Zhang and X. Chen, "Use of Multimedia in Gross Infective Pathogen Experimental Teaching", Procedia Engineering, vol. 37, (2012), pp. 64-67.

[5] W. Dai and L. Fan, "Discussion about the Pros and Cons and Recommendations for Multimedia Teaching in Local Vocational Schools", Physics Procedia, vol. 33, (2012), pp. 1144-1148.

[6] R. Khansa, "Teachers' Perceptions toward School Counselors in Selected Private Schools in Lebanon", Procedia - Social and Behavioral Sciences, vol. 185, (2015), pp. 381-387.

[7] C. Krstev and A. Trtovac, "Teaching Multimedia Documents to LIS Students", The Journal of Academic Librarianship, vol. 40, no. 2, (2014), pp. 152-162.

[8] S. Jian-hua and L. hong, "Explore the Effective Use of Multimedia Technology in College Physics Teaching”, Energy Procedia, vol. 17, (2012), pp. 1897-1900.

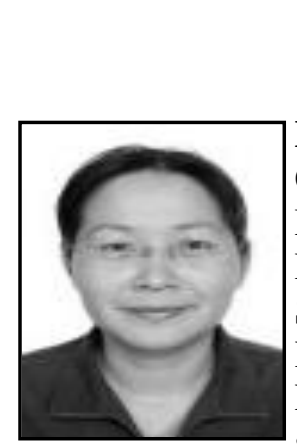

\section{Authors}

Maohong Sun, 1971.05, Hebei Cangzhou, P. R. China, Current position, grades: Associate Professor

Mailing Address: College of Animal Science and Technology, Hebei North University, HeBei Zhangjiakou 075100, P. R. China

Scientific interest: Animal and Veterinary Sciences

Publications more an 40 published

Experience: she has teaching experience of 20 year, has completed 10 scientific research projects

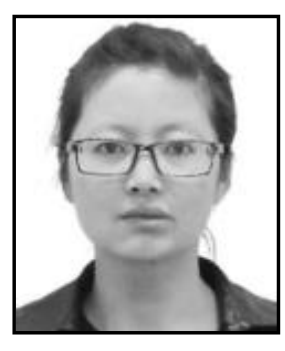

Rongchao Hao, 1981.02, Hebei Cangzhou, P. R. China

Current position, grades: Lecturer

Mailing Address: College of Animal Science and Technology, Hebei

North University, Hebei Zhangjiakou 075100, P.R. China

Scientific interest: Genetics and breeding of Animals

Publications: more than 10 papers published

Experience: She has teaching experience of 8 years, has completed three scientific research projects. 


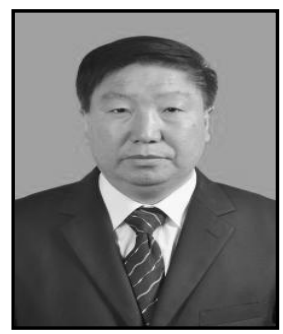

Baodi Wang, 1964.07, Hebei Yutian, P. R. China

Current position, grades: Research Associate.

College of Agriculture and Forestry, Hebei North University, HeBei Zhangjiakou 075100,P. R. China

Scientific interest: Agronomy

Publications: More than 15 published

Experience: He has teaching experience of 30 year, has completed 10 scientific research projects.

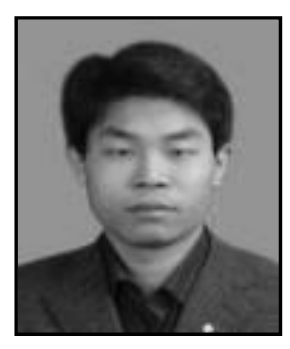

Guohua Wang, 1979.08, Hebei Zhangjiakou, P.R. China

Current position, grades: lecturer,

Mailing Address: College of Animal Science and Technology, Hebei

North University, Hebei Zhangjiakou 075100, P.R. China

Scientific interest: Genetics and breeding of Animals

Publications: more than 10 papers published

Experience: He has teaching experience of 9 years, has completed four scientific research projects.

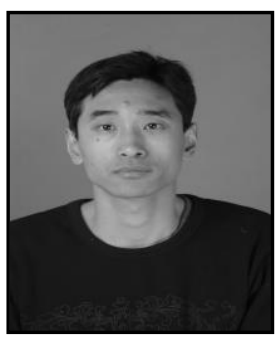

Jian Ge, 1979.04, Hebei Cangzhou, P.R. China

Current position, grades: Lecturer,

Mailing Address: College of Animal Science and Technology, Hebei North University, HeBei Zhangjiakou 075100, P. R. China

Scientific interest: Animal Husbandy

Publications: more an 30 published

Experience: he has teaching experience of 10 year, has completed 5 scientific research projects

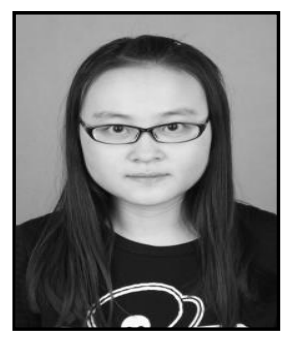

Siqi Yue, 1997.05, Luoyang, Henan, P.R. China

Current position, grades: student, Henan University of Science and Technology, Henan, 471023, China

Scientific interest: business administration

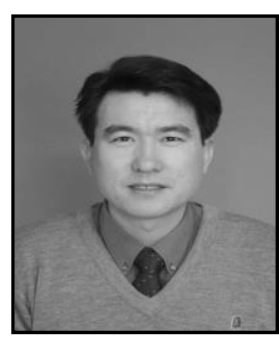

Chunwang Yue, 1969.11, Hebei Cangzhou, P.R. China

Current position, grades: Professor,

Mailing Address: College of Animal Science and Technology, Hebei

North University, HeBei Zhangjiakou 075100, P. R. China

Scientific interest: Animal and Veterinary Sciences

Publications: more an 40 published

Experience: he has teaching experience of 20 year, has completed 12 scientific research projects 
International Journal of Multimedia and Ubiquitous Engineering Vol.12, No.1 (2017) 